\title{
ERRATA
}

\section{Biochemical Basis for Whole-Cell Uptake Kinetics: Specific Affinity, Oligotrophic Capacity, and the Meaning of the Michaelis Constant}

\author{
D. K. BUTTON
}

\author{
Institute of Marine Science and Biochemistry/Molecular Biology Program, \\ University of Alaska, Fairbanks, Fairbanks, Alaska 99775
}

Volume 57, no. 7, p. 2037, legend to Fig. 3, line 7: “(this paper), alanine plus” should read “and alanine (data point 11) with."

\section{Enhanced Control of Listeria monocytogenes by In Situ-Produced Pediocin during Dry Fermented Sausage Production}

P. M. FOEGEDING, A. B. THOMAS, D. H. PILKINGTON, AND T. R. KLAENHAMMER

Department of Food Science, North Carolina State University, Raleigh, North Carolina 27695-7624

Volume 58, no. 3, p. 887, legend to Fig. 3, lines 1 and 2: "Symbols: $\bigcirc$ and $\odot$, P. acidilactici PAC 1.0 Str ${ }^{r}$ Rif'; $\triangle$ and $\boldsymbol{\Delta}$, L. monocytogenes (pGK12) five-strain composite" should read "Symbols: $\bigcirc$ and $\odot$, L. monocytogenes (pGK12) five-strain composite; $\triangle$ and $\Delta, P$. acidilactici PAC $1.0 \mathrm{Str}^{\mathrm{r}} \mathrm{Rif}^{\mathrm{T}}$.", 